\title{
Isolation and phenotyping of potential stem cells from the umbilical cord of the bottlenose dolphin(Tursiops truncatus)
}

\author{
ANNALAURA MANCIA*,1 GIULIA ZUCCON ${ }^{1,2}$, DENISE LUNARDI ${ }^{1}$, BARBARA BIANCANI ${ }^{3}$, CLAUDIA GILI ${ }^{3}$, \\ ROSCOE STANYON ${ }^{4}$, DANIEL GARCÍA-PARRAGA ${ }^{5}$, MARA MELLADO ${ }^{6}$, LUIGI ABELLI ${ }^{1}$ \\ and VICTORIA MORENO-MANZANO ${ }^{6}$
}

\author{
${ }^{1}$ University of Ferrara, Department of Life Sciences and Biotechnology, Ferrara, Italy, ${ }^{2}$ University of Parma, Department of \\ Bioscience, Parma, Italy, ${ }^{3}$ Costa Edutainment S.p.A., Riccione, Italy, ${ }^{4}$ University of Firenze, Department of Biology, Firenze, Italy, \\ ${ }^{5}$ Fundación Oceanográfic de la Comunitat Valenciana, Oceanográfic, Ciudad de las Artes y las Ciencias, Valencia, Spain and \\ ${ }^{6}$ Neuronal and Tissue Regeneration Lab, Centro de Investigacion Principe Felipe, Valencia, Spain
}

\begin{abstract}
We have successfully isolated cells with stem-like properties from bottlenose dolphin (Tursiops truncatus) umbilical cord. Our results show that this cetacean species has embryonic fetal and adult stem cells as do humans and other studied mammals. This accomplishment allows to eventually investigate whether dolphins, due to their unique adaptations to aquatic environments, have special stem cell lineages or distinctive mechanisms of cell programming. Further characterization of their potency to differentiate into multiple cell lineages would fulfill numerous applicative purposes. We characterized, developed and refined a new protocol for obtaining potential stem cells from umbilical cord tissues of the bottlenose dolphin. Tissue samples were taken from umbilical cords of successful deliveries immediately after placenta ejection and collection from the water. Umbilical cord samples $\left(2-3 \mathrm{~cm}^{3}\right)$ were excised and subjected to enzymatic digestion and mechanical dissociation. Viable cells from specimens resident in the Oceanografic Valencia were cultured and subsequently isolated and tested for pluripotent characteristics (cell morphology, phenotype and expression of surface markers). Cell viability was confirmed also after freezing/thawing. The established protocol is suitable for collection/isolation/culture of dolphin potential mesenchymal stem cells from dolphin umbilical cord, which can be deposited in cell banks for future research needs.
\end{abstract}

KEY WORDS: marine mammal, injury, mesenchymal stem cell, cryopreservation, stem cell banking

\section{Introduction}

Bottlenose dolphin (BD), Tursiops truncatus, is a species highly represented in zoological and marine parks worldwide. It has been thoroughly described in publications for scientific and non-scientific audience, reaching an enormous popularity even through movies and TV shows. BDs can experience skin injuries (rakemarks) and external soft tissue, up to bone damage, through their lives as a result of daily activity and/or social interactions. Nevertheless, the very efficient and fast wound healing mechanisms described in dolphins may limit infection processes associated with open wounds (Zasloff, 2011). Scientists have been trying to isolate dolphin cells for a long time (Cecil and Nigrelli, 1970) but, despite the great efforts, their availability is still limited, also considering that primary cells need to be immortalized in order to have a long-term system for investigation (Yu et al., 2005).

Mesenchymal stem cells (MSCs) are an attractive cell population for studies of musculoskeletal tissue regeneration of and wound healing (Niemeyer et al., 2010; De Almeida et al., 2012; Wei et al., 2013). Multiple sources of MSCs have been described in humans and animals (Hill et al., 2019; Trindade et al., 2017; Barberini et al., 2014; Ullah et al., 2015), including adipose tissue, endometrium, dental tissues, bone marrow, ligaments, and lung, where they express specific cell surface markers (e.g. clusters of differentiation) (Ullah et al., 2015; Mushahary et al., 2018). Our study aimed at

Abbreviations used in this paper: APC, allophycocyanin; BD, Bottlenose dolphin; DMEM, Dulbecco's modified eagle medium; DPBS, Dulbecco's phosphate-buffered saline; DUG, dolphin umbilical cord; FITC, fluorescein isothiocyanate; GM, growth medium; MSC, mesenchymal stem cell; PE, phycoerythrin; UC, umbilical cord.

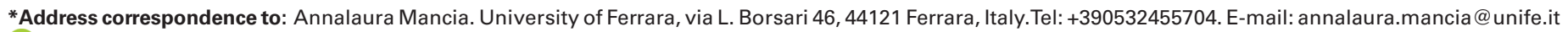
(iD) https://orcid.org/0000-0001-8680-3530
} 

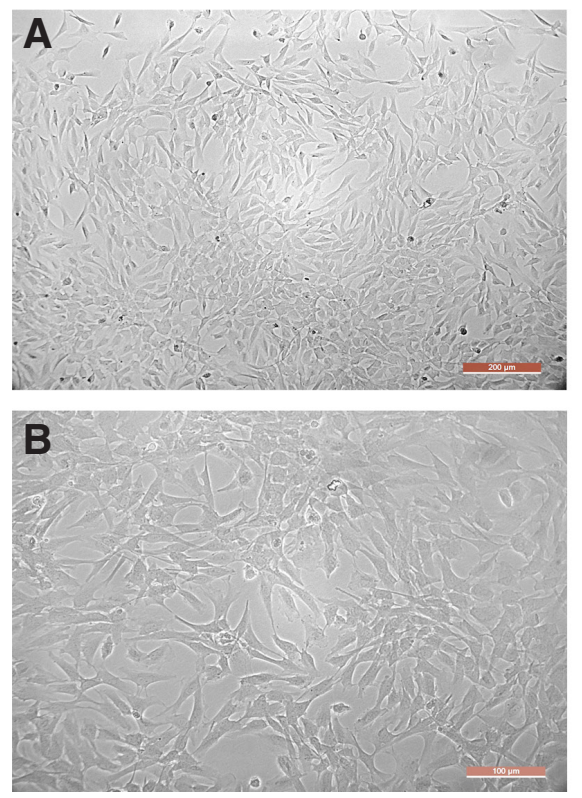

C

isolating and characterizing cells with stemeness properties from the BD umbilical cord.

\section{Experimental Protocols}

\section{Tissue collection}

Umbilical cord (UC) tissue samples were collected post-partum after placenta expulsion by an individual maintained in the Oceanográfic (Valencia, Spain). The placenta and the adjoining UC were ejected 5 hours 40 minutes after the calf delivery. The UC samples from Valencia were used in all the experiments described. UC tissue samples were also obtained from two additional female dolphins, maintained in the Acquario di Genova, and in Oltremare (Riccione), respectively 6 hours 30 minutes and 7 hours after calf delivery. These last samples were used to validate the protocol of cell isolation, culture properties and expansion procedure (described below).

\section{MSC isolation and expansion}

UC samples over a $2 \times 2 \mathrm{~cm}$ surface section area were excised, placed in a sterile Petri dish, further reduced to $2-3 \mathrm{~cm}^{3}$ fragments using sterile scalpel and forceps, then washed twice in $1 \times$ Dulbecco's phosphate-buffered saline (DPBS; Invitrogen, Carlsbad, CA, USA) supplemented with $100 \mathrm{U} / \mathrm{ml}$ penicillin and $100 \mu \mathrm{g} / \mathrm{ml}$ streptomycin (Invitrogen;Ab) to clean the tissue and remove residual blood. The tissue was divided into smaller pieces in a laminar flow hood using sterile scalpel and forceps and washed three times in Dulbecco's Modified Eagle Medium, DMEM (Lonza; DMEM/Ab). Tissue was then dissociated enzymatically overnight at $37^{\circ} \mathrm{C}$ in DPBS/Ab containing $0.07 \%$ collagenase type IA (Sigma Aldrich, Missouri, USA). The day after the digested tissue was collected and washed three times in DPBS/Ab, centrifuged (500 g, $3 \mathrm{~min}$ ), and the pellet was resuspended in growth medium GM [DMEM/ Ab supplemented with $10 \%$ heat inactivated fetal bovine serum (FBS), 2mM L-glutamine, $0.3 \% \mathrm{D}$-glucose) and plated in a $6 \mathrm{~cm}$ diameter Petri dish, incubated overnight at $37^{\circ} \mathrm{C}$. The day after the medium was removed and replaced with fresh $\mathrm{GM}$. The adhering cells, classified as potential dolphin umbilical cord mesenchymal stem cells (DUC-MSCs) were allowed to grow until nearly confluent for subsequent analytical steps.

The counting of disaggregated cells was performed using a hemocytometer on an inverted light microscope, using Trypan blue exclusion assay to check cell viability. Cells were plated on tissue culture plastic flasks in GM and incubated at $37^{\circ} \mathrm{C}$ in $5 \%$ $\mathrm{CO}_{2}, 21 \% \mathrm{O}_{2}$ atmosphere. DUC-MSCs morphology was analyzed at passage 2 using ImageJ software (http://imagej.nih.gov/ij/) on images collected with a Leica DM 6000 light microscope supported by the Leica Application Suite (LAS) software v4.5 (Leica, Buffalo Grove, IL, USA). Cells were cultured for two passages in GM medium prior to plating and expansion in T25 followed by 3xT75 tissue culture polystyrene flasks. Cells were allowed to grow until nearly confluent for freezing procedure, preceded by cell trypsinization and counts. Vials of $10^{6}$ cells were subject to slow freezing $\left(\sim 1^{\circ} \mathrm{C} /\right.$ $\mathrm{min}$ ) controlled by an isopropanol bath container (Nalgene/Thermo Scientific) in a $-80^{\circ} \mathrm{C}$ freezer. After a week cells were removed from the isopropanol bath container and stored in cryovials containers in the $-80{ }^{\circ} \mathrm{C}$ freezer for a period ranging from 1 week to several months. Three cryovials of $10^{6}$ cells from passage 3 were shipped frozen from Valencia to Italy where they were used for karyotyping (University of Florence) and further expansion and RNA extraction (University of Ferrara). For thawing, cryovials were transferred from $-80{ }^{\circ} \mathrm{C}$ freezer storage into a dry ice container, brought to a $37^{\circ} \mathrm{C}$ water bath, and rapidly thawed with agitation at $37^{\circ} \mathrm{C}$.

\section{RNA extraction and gene amplification}

A total of $10^{6}$ cells from passage 4 were used for RNA extraction using RNeasy Mini Kit (Qiagen, Hilden, Germany) according to manufacturer's instruction. PCR were performed in $50 \mu$ l total reaction mix containing $10 \mathrm{ng}$ cDNA, $19 \mu$ l nuclease-free water (Qiagen), $0.5 \mu \mathrm{M}$ forward primers (REX1F, NANOGF, SOX2F, OCT4F), 0.5 $\mu \mathrm{M}$ reverse primers (REX1R, NANOGR, SOX2R, OCT4R) and 25 $\mu \mathrm{I}$ X DreamTaq Green PCR Master Mix (Thermo Fisher Scientific, MA, USA) and run as follows: 1 cycle of $95^{\circ} \mathrm{C}$ for $3 \mathrm{~min}, 30$ cycles of $95^{\circ} \mathrm{C}$ for $30 \mathrm{sec}, 53^{\circ} \mathrm{C}$ for $30 \mathrm{sec}, 72^{\circ} \mathrm{C}$ for $30 \mathrm{sec}, 1$ final cycle of $72^{\circ} \mathrm{C}$ for $5 \mathrm{~min}$. The primersequencesfor REX1, NANOG, SOX2 
A

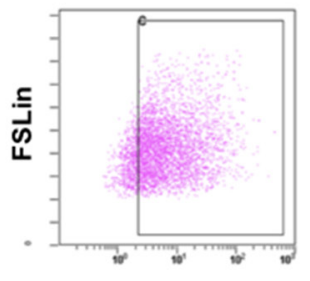

CD90 PC5
B

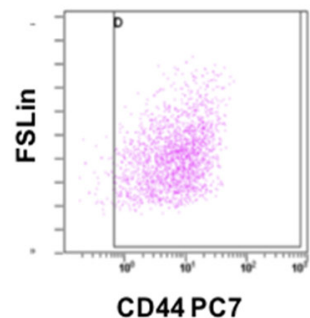

C

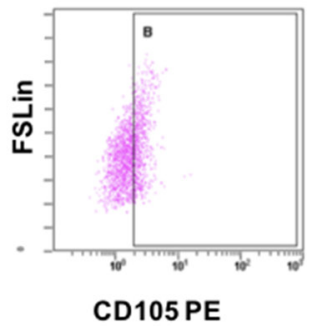

D

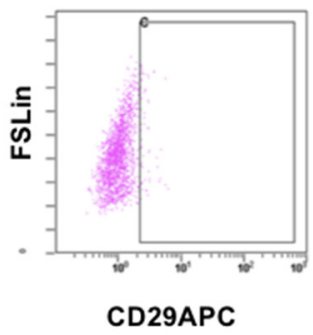

Fig. 2. Expression of stem cells markers in Dolphin umbilical cord mesenchymal stem cells (DUC-MSCs). FACS analysis of CD90-, CD44-, CD105-, and CD29-immunoreactive cells, boxed inside each plot (A-D). $X$ axis, number of cells; $Y$ axis, fluorescence measured by forward scatter FS light. (E) Agarose gel electophoresis of amplification products of the gene markers NANOG (1) OCT-4 (2), REX-1 (5) and SOX-2 (6) (lanes 3,4,7, DNA ladder, 100 bp).
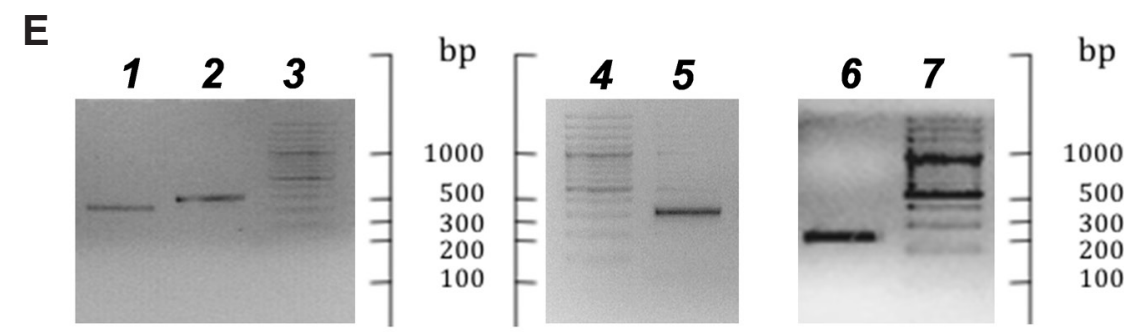

and OCT4 were designed on the gene-specific T. truncatus sequences obtained searching the dolphin genome database at www. ensembl.org [Acc.n. XM_004328739(REX1), XM_004325830.1 (NANOG), XM_004311784.1(SOX2), XM_004311235.1(OCT4) at www.ncbi.nlm.nih.gov] (TableS1). PCR products were visualized by electrophoresis (120V for $25 \mathrm{~min}$ on $2 \%$ agarose gel), then quantified and Sanger sequenced (BMR Genomics, Padova, Italy). The sequences obtained were analyzed by MEGA6 software (http:// www.megasoftware.net/) and BlastX (www.ncbi.nlm.nih.gov) to confirm gene identity.

\section{Karyotyping}

A total of $1.5 \times 10^{6}$ cells from passage 4 were subcultured from T25 flasks into three T75 flasks (Corning, Sigma-Aldrich Missouri, USA). Metaphases were harvested $48 \mathrm{hrs}$ after dividing confluent flasks and used for karyotyping. The cells were processed as follows: $3 \mathrm{hrs}$ treatment with $0.01 \mu \mathrm{g} / \mathrm{ml}$ Colcemid $^{\mathrm{TM}}$, centrifuged (1200 rpm for $10 \mathrm{~min}$ ) to remove supernatant, exposed for $20 \mathrm{~min}$ at $37^{\circ} \mathrm{C}$ to a hypotonic treatment $(10 \mathrm{ml}, 1: 1$ mixture of $0.075 \mathrm{M}$ $\mathrm{KC} 1$ and $0.4 \%$ sodium citrate). The cells were prefixed by adding $500 \mu$ fixing solution (3:1, methanol:acetic acid) and then pelleted by centrifugation and resuspended in $5 \mathrm{ml}$ fixing solution. The fixing solution was changed two times by centrifugation and resuspension. Slides were prepared according to standard procedures. Briefly, after final centrifugation, cells were resuspended in small amount of fixative and dropped onto slides cleaned in ethanol with $1 \%$ $\mathrm{HCl}$. The slides were aged by overnight incubation at $65^{\circ} \mathrm{C}$. Slides were GTG-banded followed Seabright (1971). Briefly, slides were incubated for 1.5 to 2 min in a $0.05 \%$ trypsin solution in PBS at pH 7.2. The slides were then rinsed in Hank's balanced salt solution (HBSS) for $15 \mathrm{sec}$ and stained with $2 \%$ Giemsa solution in 10\% Sorensen's buffer, pH 6.8, for $30 \mathrm{~min}$.

\section{Flow cytometry}

A total of $3 \times 10^{5}$ cells from passage 4 was used for flow cytometry. Cells were pelleted and resuspended in warm medium minus nonessential amino acid, NEAA (Thermo Fisher Scientific, MA, USA) to obtain three vials of $100 \mu$ l each. Five $\mu$ l of FITC-labelled mouse monoclonal antibody anti-human CD45 (560976, BD Pharmigen Biosciences, San Josè, CA, USA) were added to vial $1 ; 5 \mu$ of phycoerythrin (PE)-labelled mouse monoclonal antibody antirecombinant vaccinia virus containing human CD105 (L-isoform) cDNA (ab53321, Abcam, Cambridge, UK), $5 \mu$ l of PE-Cy7 labelled mouse monoclonal antibody anti-human CD44 (560533, BD Pharmigen Biosciences), and $5 \mu$ of allophycocyanin (APC)-labelled mouse monoclonal antibody anti-purified human $\alpha 5 \beta 1$ fibronectin receptor (CD29) (561794, BD Pharmigen Biosciences)were added to vial 2; $5 \mu \mathrm{l}$ of R- phycoerythrin covalently linked to cyanin 5.1 (PC5) mouse monoclonal antibody anti-CD90 (PN IM3703, Beckman Coulter) were added to vial 3.

All vials were incubated for $1 \mathrm{~h}$ at room temperature, in the dark. Then $1 \mathrm{ml}$ DPBS was added to each vial and were centrifuged (300 x $\mathrm{g}$ for $5 \mathrm{~min}$ ), the pellet was resuspended in $500 \mu \mathrm{l}$ fresh DPBS and covered with aluminum foil prior analysis in Cytomics FC 500 (Beckman Coulter, Brea, CA, USA). The antibodies used in this experiment were previously tested and validated (Johnson et al., 2012, Griffeth et al., 2014).

A total of $1.5 \times 10^{9}$ cells from passage 3wereresuspended in cryopreserving medium [CM: Dulbecco's Modified Eagle Medium (DMEM), Invitrogen], supplemented with $10 \%$ high quality dimethyl sulfoxide and 10\% FBS (Sigma Aldrich, Missouri, USA) and slowly freezed $\left(\sim 1^{\circ} \mathrm{C} / \mathrm{min}\right)$ controlled by an isopropanol bath container (Nalgene/Thermo Scientific) in a $-80{ }^{\circ} \mathrm{C}$ freezer.

\section{Results and Discussion}

Cells with stemness properties were successfully isolated and characterized from dolphin umbilical cord (DUC-MSCs). The cells grew well for up to 9-10 passages in culture before senescence (Fig. 1). They were adherent to plastic with a spindle morphology defined by their circularity and axial ratio (major/minor axis) $(0.310$ \pm 0.096 and $2.93 \pm 1.28$, respectively); average spread area was $1812 \pm 448 \mu \mathrm{m}^{2}$ (Fig. 1). Throughout the culture process, the cells retained their characteristic spindle shape and reached $80-90 \%$ 
confluence with a doubling time of seven days. The shape and size of DUC-MSCs were similar to the adipose tissue derived SCs from dolphin and other marine and terrestrial mammals (Johnson et al., 2012; Hoogduijn et al., 2013; Griffeth et al., 2014). Differently from other MSCs described in the same or other species, DUC-MSCs grew very slowly, suggesting species-specific characteristics or, most likely, the need for optimization of media composition and/or culture parameters, which are currently standardized on cultured cells of terrestrial mammals.

DUC-MSCs were also characterized for number and morphology of chromosomes to exclude aberrations due to culture conditions. The G-banding pattern confirmed the normal karyotype $(2 \mathrm{n}=44)$ previously described in T. truncatus (Stephen et al., 2015) (Fig. 1, C). Karyotyping also showed the male gender $(X Y)$ of the dolphin calf born in Valencia.

Typical SC-specific markers, such as Rex-1, Sox-2, Oct-4, and Nanog, were notably expressed. Subamniotic MSCs did not lose Oct-4 and Nanog expression after freeze-thawing. Moreover, significant expression of typical SC specific markers was observed. FACS analysis on DUC-MSCs for CD90, CD44 and CD105 are shown in Figure 2 (A-C). These surface protein markers were specifically expressed on $85 \%$ cells $\left(C D 90^{+}\right), 99 \%\left(C D 44^{+}\right)$and $35 \%\left(C D 105^{+}\right)$. Differently from what is described in human MSCC umbilical cord derived the fraction of CD29+ was much lower (3\%) (Fig. 2, D) (Carrade and Borjesson, 2013; Tong et al., 2011).

The expression of SC markers was also verified at transcriptomic level to investigate the gene expression mechanisms regulating the pluripotency property of the cells. Specifically, REX1, OCT4, NANOG and SOX2 were chosen from literature as marker of stemness (Loh et al., 2006; Zhang and Cui, 2014; Lamoury et al., 2016). OCT4 (octamer-binding transcription factor 4 or POU5F1 - POU domain, class 5, transcription factor 1) and NANOG are transcription factors required to maintain the pluripotency and self-renewal of embryonic SC through the control of a cascade of pathways that are intricately connected to govern pluripotency, self-renewal, genome surveillance and cell fate determination. SOX2 (SRY sex determining region $Y$ - box 2), a member of the SoxB1 transcription factor family, is an important transcriptional regulator in pluripotent SCs. Together with OCT4 and NANOG, SOX2 co-operatively controls gene expression in pluripotent SCs and maintain their pluripotency. Furthermore, SOX2 plays an essential role in somatic cell reprogramming, reversing the epigenetic configuration of differentiated cells back to a pluripotent embryonic state (Zhang and Cui, 2014). Amplification products had the expected size for REX1 (318 bp), NANOG (232 bp), OCT4 (267 bp) and SOX2 (244 bp) (Fig. 2, E). Sequencing confirmed the identity of amplified products. Following expansion at passage 4, DUCMSCs were slowly frozen in CM as previously described (Mancia et al., 2012) and subsequently thawed, ensuring the safety and efficacy of cryopreservation andestablishing the prospect of SC banking. The use of SCs is a promising novel approach for the treatment of many diseases and injuries in veterinary care. UC membrane represents a valuable source for MSCs, because they are abundant sources and there are less ethical issues unlike embryonic SCs. Here we describe the first isolation of potential stem cells from BD-UC. These could provide a safe and efficient treatment for tissue injuries, and therapies offering a great alternative to more invasive, time-consuming isolation/proliferation of autologous MSCs from a live dolphin.

\section{Conclusions}

The protocol presented here is a practical alternative to more invasive and time-consuming methods for isolation/proliferation of autologous mesenchymal stem cells from live individuals. The availability of an easily renewable source of dolphin stem cells from marine parks could aid the investigation of the unique and specific properties of mesenchymal stem cells and all derived cell lines in dolphin vs human, whilst being novel in vitro models of cell and tissue differentiation, for morphogenesis and comparative developmental biology studies. These research avenues have potential biomedical applications in regenerative medicine and the treatment of immune disorders.

\section{Competing interests}

The authors declare no competing financial interest.

\section{Funding}

This work is supported by a research grant from the University of Ferrara (Iniziative di internazionalizzazione dell'Ateneo 2014) to A. Mancia.

\section{Authors' contributions}

AM was a major contributor in experimental design, data acquisition, statistical analysis and writing of the manuscript. CG, DGP and BB were major contributors to sample retrievement and collection. VMM, MM and $R S$ were contributors for data acquisition and analysis. LA was contributor in data interpretation and critical analysis of the manuscript. All authors have read, reviewed and approved the final manuscript.

\section{Acknowledgements}

We thank the technical team and trainers from Acquario di Genova, Oltremare (Riccione), and Oceanográfic (Valencia) for the support in the logistic of sample collection and immediate manipulation.

\section{Ethics approval}

The umbilical cords were collected from three Tursiops truncatus females maintained in zoological institutions operating within the zoo directive framework (EU 22/1999) in Italy and Spain that regulates husbandry and management of zoo animals. The samples were collected without physical manipulation or disturbance of the females and their calves, and utilized for the routine veterinary checks of the placentas after birth.

\section{Availability of data and materials}

All data generated or analyzed during this study are included in this published article. Samples (e.g. DUC-MSCS) are available from the corresponding author on reasonable request.

\section{References}

BARBERINI DJ, FREITAS NP, MAGNONI MS, MAIA L, LISTONI AJ, HECKLER MC SUDANO MJ, GOLIM MA, DA CRUZ LANDIM-ALVARENGA F, AMORIM RM (2014). Equine mesenchymal stem cells from bone marrow, adipose tissue and umbilical cord: immunophenotypic characterization and differentiation potential. Stem Cell Res Ther 5: 25.

CARRADE DD, BORJESSON DL. Immunomodulation by mesenchymal stem cells inveterinary species. Comp Med. 63: 207-217.

CECIL JT, NIGRELLI RF (1970). Cell cultures from marine mammals. J Wildl Dis 19706: 494-495.

DE ALMEIDAAM, DEMANGE MK, SOBRADO MF, RODRIGUES MB, PEDRINELLI A, HERNANDEZ AJ (2012). Patellar tendon healing with platelet-rich plasma: a prospective randomized controlled trial. Am J Sports Med40: 1282-1288.

GRIFFETH RJ, GARCÍA-PÁRRAGA D, MELLADO-LÓPEZ M, CRESPO-PICAZO JL, SORIANO-NAVARRO M, MARTINEZ-ROMERO A, MORENO-MANZANO 
V (2014). Platelet-rich plasma and adipose-derived mesenchymal stem cells for regenerative medicine-associated treatments in bottlenose dolphins (Tursiops truncatus). PLoS One 9: e108439.

HILL ABT, BRESSAN FF, MURPHY BD, GARCIA JM (2019). Applications of mesenchymal stem cell technology in bovine species. Stem Cell Res Ther 10: 44.

HOOGDUIJN MJ, VAN DENBEUKELJC, WIERSMALC, IJZER J (2013). Morphology and size of stem cells from mouse and whale: observational study. BMJ347: 6833 .

JOHNSON SP, CATANIAJM, HARMANRJ, JENSEN ED (2012). Adipose-derived stem cell collection and characterization in bottlenose dolphins (Tursiops truncatus). Stem Cells Dev 21: 2949-2957.

LAMOURY FM, CROITORU-LAMOURY J, BREW BJ (2006). Undifferentiated mouse mesenchymal stem cells spontaneously express neural and stem cell markers Oct-4 and Rex-1. Cytotherapy 8: 228-242.

LOHYH, WU Q, CHEW JL, VEGA VB, ZHANG W, CHEN X, BOURQUE G, GEORGE J, LEONG B, LIU J, WONG KY, SUNG KW, LEE CW, ZHAO XD, CHIU KP, LIPOVICH L, KUZNETSOV VA, ROBSON P, STANTON LW, WEI CL, RUAN Y, LIM B, $\mathrm{NG} \mathrm{HH}$ (2006). The Oct4 and Nanog transcription network regulates pluripotency in mouse embryonic stem cells. Nat Genet 38: 431-440.

MANCIA A, SPYROPOULOS DD, MCFEE WE, NEWTON DA, BAATZ JE (2012). Cryopreservation and in vitro culture of primary cell types from lung tissue of a stranded pygmy sperm whale (Kogia breviceps). Comp Biochem PhysiolC Toxicol Pharmacol 155: 136-142

MUSHAHARY D, SPITTLER A, KASPER C, WEBER V, CHARWAT V (2018). Isolation, cultivation, and characterization of human mesenchymal stem cells. Cytometry $A$ 93: 19-31.

NIEMEYER P, FECHNER K, MILZS, RICHTER W, SUEDKAMP NP, MEHLHORNAT,
PEARCE S, KASTENP (2010). Comparison of mesenchymal stem cells from bone marrow and adipose tissue for bone regeneration in a critical size defect of the sheep tibia and the influence of platelet-rich plasma. Biomaterials 31:3572-3579.

SEABRIGHT M (1971). A rapid banding technique for human chromosomes. Lancet 2: $971-972$.

STEPHEN J. O'BRIEN, JOAN C. MENNINGER, WILLIAM G. NASH(Ed) (2006). Atlas of Mammalian Chromosomes. John Wiley \& Sons Inc, Hoboken, NJ.

TONG CK, VELLASAMY S, TAN BC, ABDULLAH M, VIDYADARAN S, SEOW HF, RAMASAMY R (2011). Generation of mesenchymal stem cell from human umbilical cord tissue using a combination enzymatic and mechanical disassociation method. Cell Biol Int 35: 221-226.

TRINDADEAB, THERRIEN J, GARCIAJM, SMITHLC (2017). Mesenchymal-like stem cells in canine ovary show high differentiation potential. Cell Prolif 50: e12391.

ULLAH I, SUBBARAO RB, RHO GJ (2015). Human mesenchymal stem cells - current trends and future prospective. Bio Sci Rep 35: e00191.

WEI X, YANG X, HAN ZP, QU FF, SHAO L, SHI YF (2013). Mesenchymal stem cells: a new trend for cell therapy. Acta Pharmacol Sin 34: 747-754.

YUJ, KINDY MS, ELLISBC, BAATZJE, PEDEN-ADAMS M, ELLINGHAMTJ, WOLFF DJ, FAIR PA, GATTONI-CELLI S (2005). Establishment of epidermal cell lines derived from the skin of the Atlantic bottlenose dolphin (Tursiops truncatus). Anat Rec A Discov Mol Cell Evol Biol 287: 1246-1255.

ZASLOFFM (2011). Observations on the remarkable (and mysterious) wound-healing process of the bottlenose dolphin. J Invest Dermatol 131: 2503-2505.

ZHANG S, CUI W (2014). Sox2, a key factor in the regulation of pluripotency and neural differentiation. World J Stem Cells 6: 305-311. 


\section{Further Related Reading, published previously in the Int. J. Dev. Biol.}

Plasticity of human adipose-derived stem cells - relevance to tissue repair

Leonardo Guasti, Sophie E. New, Irene Hadjidemetriou, Miriam Palmiero and Patrizia Ferretti

Int. J. Dev. Biol. (2018) 62: 431-439

https://doi.org/10.1387/ijdb.180074pf

Disruption of the aortic wall by coelomic lining-derived mesenchymal cells accompanies the onset of aortic hematopoiesis

Alaa A. Arraf, Marella F.T.R. De Bruijn and Thomas M. Schultheiss

Int. J. Dev. Biol. (2017) 61: 329-335

https://doi.org/10.1387/ijdb.170012ts

Growth factor-defined culture medium for human mesenchymal stem cells

Sumiyo Mimura, Naohiro Kimura, Mitsuhi Hirata, Daiki Tateyama, Midori Hayashida, Akihiro Umezawa, Arihiro Kohara, Hiroki Nikawa, Tetsuji Okamoto and Miho K. Furue

Int. J. Dev. Biol. (2011) 55: 181-187

https://doi.org/10.1387/ijdb.103232sm

Epiblast-derived stem cells in embryonic and adult tissues

Maria P. De-Miguel, Francisco Arnalich-Montiel, Pilar Lopez-Iglesias, Alejandro Blazquez-Martinez and Manuel Nistal

Int. J. Dev. Biol. (2009) 53: 1529-1540

https://doi.org/10.1387/ijdb.072413md

Genetic and epigenetic instability of human bone marrow mesenchymal stem cells expanded in autologous serum or fetal bovine serum

John-Arne Dahl, Shivali Duggal, Neralie Coulston, Douglas Millar, John Melki, Aboulghassem Shahdadfar, Jan E. Brinchmann and Philippe Collas

Int. J. Dev. Biol. (2008) 52: 1033-1042

https://doi.org/10.1387/ijdb.082663jd

A novel, neural potential of non-hematopoietic human umbilical cord blood stem cells Krystyna Domanska-Janik, Leonora Buzanska and Barbara Lukomska

Int. J. Dev. Biol. (2008) 52: 237-248

https://doi.org/10.1387/ijdb.072315kd

An efficient method for isolation of murine bone marrow mesenchymal stem cells Samad Nadri, Masoud Soleimani, Reza H. HosSeni, Mohammad Massumi, Amir Atashi and Reza Izadpanah
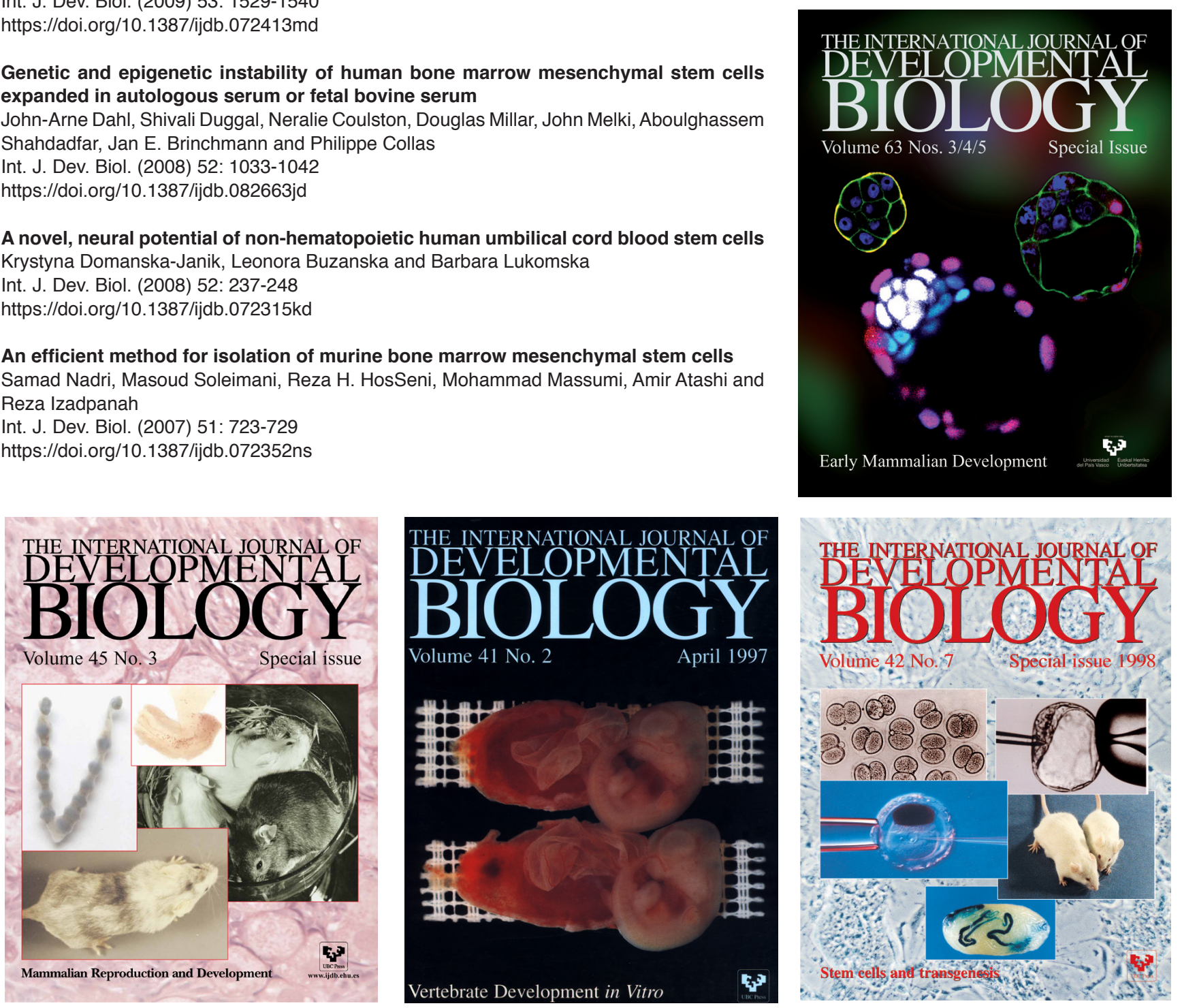